Check for updates

Cite this: RSC Adv., 2018, 8, 1632

Received 18th September 2017 Accepted 6th December 2017

DOI: $10.1039 / \mathrm{c} 7 \mathrm{ra10367k}$

rsc.li/rsc-advances

\section{A $\mathrm{LiAlO}_{2} /$ nitrogen-doped hollow carbon spheres (NdHCSs) modified separator for advanced lithium-sulfur batteries $\dagger$}

\author{
Fanqun Li, Furong Qin, (D) Guanchao Wang, Kai Zhang, (D) Peng Wang, Zhian Zhang iD \\ and Yanqing Lai (iD *
}

Lithium-sulfur (Li-S) batteries have gained significant attention due to their ultrahigh theoretical specific capacity and energy density. However, their practical commercialization is still facing many intractable problems, of which the most difficult is the shuttle effect of dissolved polysulfides. To restrict the shuttle of polysulfides, herein, a novel double-layer lithium aluminate/nitrogen-doped hollow carbon sphere $\left(\mathrm{LiAlO}_{2} / \mathrm{NdHCSs}\right)$-modified separator was designed. The upper NdHCSs layer on the separator works as the first barrier to physically and chemically adsorb polysulfides, whereas the bottom $\mathrm{LiAlO}_{2}$ layer acts as the second barrier to physically block the polysulfides without restricting the $\mathrm{Li}^{+}$transport due to the high ionic conductivity of $\mathrm{LiAlO}_{2}$. Cells with the $\mathrm{LiAlO}_{2} / \mathrm{NdHCSs}$-modified separator showed an initial discharge capacity of $1500 \mathrm{~mA} \mathrm{~h} \mathrm{~g}^{-1}$ at $0.2 \mathrm{C}$, and a discharge capacity of $543.3 \mathrm{~mA} \mathrm{~h} \mathrm{~g} \mathrm{~m}^{-1}$ was obtained after 500 cycles at 2C. Especially, when the areal density of the active material was increased to $4.5 \mathrm{mg}$ $\mathrm{cm}^{-2}$, the cells retained a discharge capacity of $538.6 \mathrm{~mA} \mathrm{~h} \mathrm{~g}$ after 100 cycles at $0.5 \mathrm{C}$. The outstanding electrochemical performance of $\mathrm{Li}-\mathrm{S}$ cells with the $\mathrm{LiAlO}_{2} / \mathrm{NdHCSs}$-modified separators show a new approach for the applications of Li-S batteries.

\section{Introduction}

The scarcity of fossil fuels and the ever-growing environmental problems promote the development of renewable energy technologies such as fuel cells, metal-air batteries, and other secondary batteries. ${ }^{\mathbf{1}, 2}$ Lithium-sulfur (Li-S) batteries have been regarded as one of the most promising candidates for the nextgeneration energy storage systems. The theoretical specific capacity of sulfur is as high as $1675 \mathrm{~mA} \mathrm{~h} \mathrm{~g}^{-1}$, and the theoretical energy density of a $\mathrm{Li}-\mathrm{S}$ battery based on a $\mathrm{Li}$ anode and a S cathode is $\sim 2600 \mathrm{~W} \mathrm{~h} \mathrm{~kg}^{-1} \cdot \cdot^{3-6}$ Moreover, the environmental benignity and natural abundance of the elemental sulfur make $\mathrm{Li}-\mathrm{S}$ batteries more attractive to both the academic and industrial communities. ${ }^{7,8}$ It was reported that the practical energy density of packaged Li-S batteries could be $400-600 \mathrm{~W} \mathrm{~h} \mathrm{~kg}^{-1}$, which was much higher than that of the commercial $\mathrm{LiCoO}_{2} / \mathrm{C}$ batteries..$^{9-11}$ However, there are some intractable issues, such as low utilization of sulfur, poor cycle stability, and dissolution of the intermediates formed in the discharge-charge processes, hindering the practical applications of $\mathrm{Li}-\mathrm{S}$ batteries. It is recognized that sulfur and its final discharge products $\left(\mathrm{Li}_{2} \mathrm{~S}_{2}\right.$ or $\mathrm{Li}_{2} \mathrm{~S}$ ) show ultralow ionic and electronic conductivity, which in

School of Metallurgy and Environment, Central South University, Changsha, Hunan 410083, China. E-mail: laiyanqingcsu@163.com

$\dagger$ Electronic supplementary information (ESI) available. See DOI: $10.1039 / \mathrm{c} 7 \mathrm{ra10367k}$ turn is responsible for the low utilization of active materials. ${ }^{\mathbf{1 2 , 1 3}}$ Dissolution of the intermediates $\left(\mathrm{Li}_{2} \mathrm{~S}_{x}, 3 \leq x \leq 8\right)$ not only causes a continuous loss of active materials, but also results in shuttle phenomenon that leads to a low coulombic efficiency. ${ }^{\mathbf{1 4 - 1 6}}$ In addition, huge volume expansion $(\sim 80 \%)$ occurs during discharge processes due to the different volume densities of $\mathrm{S}$ and $\mathrm{Li}_{2} \mathrm{~S}$, which would results in an unstable structure of the electrode. ${ }^{17,18}$

In the past few years, many efforts have been dedicated towards improving the electrochemical performance of $\mathrm{Li}-\mathrm{S}$ batteries mainly through designing various porous architectures to confine sulfur. Hosts for accommodating insulating sulfur include carbon materials, ${ }^{19-22}$ polymers, ${ }^{23-25}$ inorganic oxides, ${ }^{7,8,26}$ and other organic compounds. ${ }^{27}$ These materials have shown remarkable improvement in the performance of Li-S batteries because they can provide high electrical conductivity for the sulfur cathode and confine the active materials within the porous structure with physical or chemical entrapment, thus restricting the shuttle of polysulfides (PS). However, for better performance, sulfur needs to be well dispersed within the pores of the host material. This involves complex fabrication processes, which in turn makes sulfur inconvenient to be used in practical application for $\mathrm{Li}-\mathrm{S}$ batteries. ${ }^{28-30}$

Construction of a new cell configuration to restrict the shuttle of polysulfides is demonstrated to be another effective way to improve the electrochemical performance of lithium- 
sulfur batteries. This involves insertion of interlayers with high physical or chemical adsorbability between the conventional sulfur cathode and the separator ${ }^{\mathbf{1 4 3 1}-33}$ and introduction of adsorption layers on the top surface of the conventional sulfur cathode (cathode modification), ${ }^{34}$ or on the side of the separator facing the sulfur cathode (separator modification). ${ }^{28,30,35}$ These layers not only restrict the shuttle of polysulfides but also provide extra active sites for the deposits of $\mathrm{Li}_{2} \mathrm{~S}_{2}$ or $\mathrm{Li}_{2} \mathrm{~S}$. With these new configurations, conventional sulfur cathodes that fabricated by simple mixing could be directly used for the cellassembly, avoiding complicated procedures for preparing sulfur-based composites. Specifically, separator modification is more achievable since a separator possesses good mechanical ability and flexibility. Many materials, including carbon materials, ${ }^{28}$ polymers, ${ }^{36,37}$ metal oxides, ${ }^{38-40}$ metal sulphides, ${ }^{41}$ and hybrid materials, ${ }^{29,30}$ with different functionalities have been applied to construct layers on the separators. With these modified separators, Li-S batteries have shown excellent electrochemical performances. Although these layers can physically or chemically entrap the dissolved polysulfides, some of them can still penetrate the separator. Lately, Bai et al. used a metalorganic framework (MOF) to modify the separator for lithiumsulfur batteries. ${ }^{42}$ The MOF was used as an ionic sieve to restrict the shuttle of $\mathrm{S}_{x}{ }^{2-}$ anions, which resulted in an ultra-long cycle life.

Inspired by this, herein, we proposed the use of the ionic conductor $\mathrm{LiAlO}_{2}$ and nitrogen-doped hollow carbon spheres (NdHCSs) to construct double layers on the commercial polymer separator to significantly minimize the shuttle of polysulfides. The NdHCSs on the upper layer serve as a secondary current collector and the first absorption layer, whereas $\mathrm{LiAlO}_{2}$ at the bottom layer blocks the pores of the separator to restrict the penetration of polysulfides. Since $\mathrm{LiAlO}_{2}$ possesses excellent lithium ion conductivity (up to $3 \times 10^{5} \Omega^{-1} \mathrm{~cm}^{-1}$ ), ${ }^{43,44}$ the transport of lithium ions is not affected. With the $\mathrm{LiAlO}_{2} /$ NdHCSs-modified separator, the initial discharge capacity is increased from 1013.7 to $1500 \mathrm{~mA} \mathrm{~h} \mathrm{~g}^{-1}$ at $0.2 \mathrm{C}$. Even at a high current density of $2 \mathrm{C}$, the cells retained a discharge capacity of $543.3 \mathrm{~mA} \mathrm{~h} \mathrm{~g}^{-1}$ after 500 cycles. In addition, when the areal sulfur loading was increased to 3.0 and $4.5 \mathrm{mg} \mathrm{cm}^{-2}$, the $\mathrm{Li}-\mathrm{S}$ cells demonstrated the discharge capacities of 640 and $538.6 \mathrm{~mA} \mathrm{~h} \mathrm{~g}^{-1}$ after 100 cycles at $0.5 \mathrm{C}$, respectively.

\section{Experimental}

\subsection{Material preparation}

NdHCSs were obtained using the same synthetic protocols mentioned in our earlier reports. ${ }^{45}$ Typically, silica spheres $(2 \mathrm{~g}$, Sigma-Aldrich, $140 \mathrm{~nm}$ ) were used as the templates and mixed with dopamine ( $2 \mathrm{~g}$, Sigma-Aldrich) in a Tris-buffer solution (250 mL, pH 8.5) for polymerization under vigorous stirring for $24 \mathrm{~h}$. The polydopamine/ $\mathrm{SiO}_{2}$ composite was obtained by filtration and dried at $80^{\circ} \mathrm{C}$. Thereafter, it was carbonized under an argon flow at $400{ }^{\circ} \mathrm{C}$ for two hours (heating rate was $1{ }^{\circ} \mathrm{C} \min ^{-1}$ ), followed by another three hours at $800{ }^{\circ} \mathrm{C}$ (heating rate was $\left.5{ }^{\circ} \mathrm{C} \min ^{-1}\right)$. After natural cooling, the sample was washed in a HF aqueous solution (15 wt $\%$ ) for $24 \mathrm{~h}$. For the preparation of $\mathrm{LiAlO}_{2}, \mathrm{Al}\left(\mathrm{NO}_{3}\right)_{3} \cdot 9 \mathrm{H}_{2} \mathrm{O}(1.42 \mathrm{~g})$ was mixed with $\mathrm{LiOH} \cdot \mathrm{H}_{2} \mathrm{O}(0.32 \mathrm{~g})$ in distilled water $(200 \mathrm{~mL})$. Then, an appropriate amount of ammonia was added to the solution under magnetic stirring to form a gel. After drying, the resultant product was transferred into a tube furnace and calcinated in air at $500{ }^{\circ} \mathrm{C}$ for $4 \mathrm{~h}$ (heating rate was $5{ }^{\circ} \mathrm{C} \min ^{-1}$ ). After washing with deionized water and drying, pure $\mathrm{LiAlO}_{2}$ was obtained.

The $\mathrm{LiAlO}_{2} / \mathrm{NdHCSs}$-modified separator was prepared by a two-step casting procedure. At first, $\mathrm{LiAlO}_{2}$ (90 wt $\%$ ) was mixed with PVDF (10 wt\%) using $N$-methyl-2-pyrrolidone (NMP) as the dispersant to make a slurry, which was then coated on a piece of polymer separator (Celgard 2325) via the doctor-blade technique. After drying at $60{ }^{\circ} \mathrm{C}$, the slurry composed of $\mathrm{NdHCSs} / \mathrm{PVDF}(9: 1)$ was applied on the top of the $\mathrm{LiAlO}_{2}$ layer via the same procedure. Then, the separator was shaped into a circular membrane with a diameter of $19 \mathrm{~mm}$ after drying.

\subsection{Material characterization}

Field emission scanning electron microscopy (SEM, Nova Nano SEM 230 or MIRA 3 LMU) was employed to characterize the morphology. Elements on the surface of the sample were identified by energy-dispersive X-ray spectroscopy (EDX). X-ray diffraction (XRD) measurements were performed using Rigaku $3014(\mathrm{Cu}-\mathrm{K} \alpha)$. The size distribution of NdHCSs was obtained by the Nano Measurer software.

\subsection{Electrochemical measurements}

A sulfur cathode was prepared by mixing elemental sulfur (70 wt\%), carbon black (Super P, $20 \mathrm{wt} \%$ ), and PVDF (10 wt\%) to make a slurry with NMP as the dispersant. Then, this slurry was casted onto a piece of aluminium foil with doctor-blade and then dried at $50{ }^{\circ} \mathrm{C}$ in a vacuum oven for $24 \mathrm{~h}$. Then, the electrode was shaped into a circular disk with a diameter of $13 \mathrm{~mm}$. The sulfur loading of sulfur cathodes was tailored by controlling the thickness of the slurry. Li-S cells were assembled in an argon filled glove box. A lithium foil was used as the anode. The electrolyte consisted of $1 \mathrm{M}$ lithium bis(trifluoromethanesulfonyl)imide (LiTFSI) and $0.2 \mathrm{M} \mathrm{LiNO}_{3}$ in a mixture of DOL/DME $(1: 1, \mathrm{v} / \mathrm{v})$. For the assembly, $30 \mathrm{~mL} \mathrm{~g}_{\text {sulfur }}{ }^{-1}$ of electrolyte was added to each cell. Cyclic voltammetry (CV) measurement was performed using a multichannel electrochemical test system (1470E/1400A, Solartron) in the voltage range of $2.8-1.8 \mathrm{~V}$ at a scanning rate of $0.2 \mathrm{mV} \mathrm{s}^{-1}$.

\section{Results and discussion}

The schematic of the $\mathrm{LiAlO}_{2} / \mathrm{NdHCSs}$-modified separator and the corresponding $\mathrm{Li}-\mathrm{S}$ cell configuration are presented in Fig. 1. The $\mathrm{LiAlO}_{2} / \mathrm{NdHCSs}$-modified separator possesses a sandwich structure where $\mathrm{LiAlO}_{2}$ layer is located between the commercial polymer separator and the NdHCSs layer. When the dissolution of polysulfides occur, the shuttle of polysulfides is partially adsorbed by the NdHCSs layer with a strong physical and chemical adsorbability. The rest of the polysulfides penetrating the NdHCSs layer are blocked by the $\mathrm{LiAlO}_{2}$ layer. Therefore, the loss of active materials is minimized; this results 


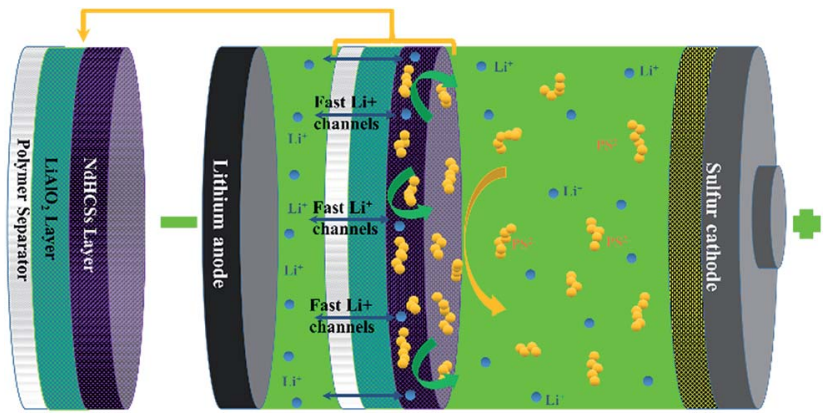

Fig. 1 Schematic of the $\mathrm{LiAlO}_{2} / \mathrm{NdHCSs}$-modified separator and the corresponding $\mathrm{Li}-\mathrm{S}$ cell configuration.

in higher utilization of sulfur and higher coulombic efficiency. The morphology of the $\mathrm{LiAlO}_{2} / \mathrm{NdHCSs}$-modified separator was investigated first via SEM. As shown in the SEM image presented in Fig. 2(a), the sandwich structure of the modified separator is well observed, which demonstrates that the $\mathrm{LiAlO}_{2} /$ NdHCSs-modified separator is successfully fabricated. EDS mapping results (Fig. 2(b and c)) further demonstrate the interfaces of the separator-LiAlO ${ }_{2}$ and $\mathrm{LiAlO}_{2}-\mathrm{NdHCSs}$. To demonstrate that the pores of the modified separator are blocked by the $\mathrm{LiAlO}_{2}$ layer, the top view SEM image of the modified separator (obtained from the side without layers) is presented in Fig. 2(d), from which it can be clearly seen that the

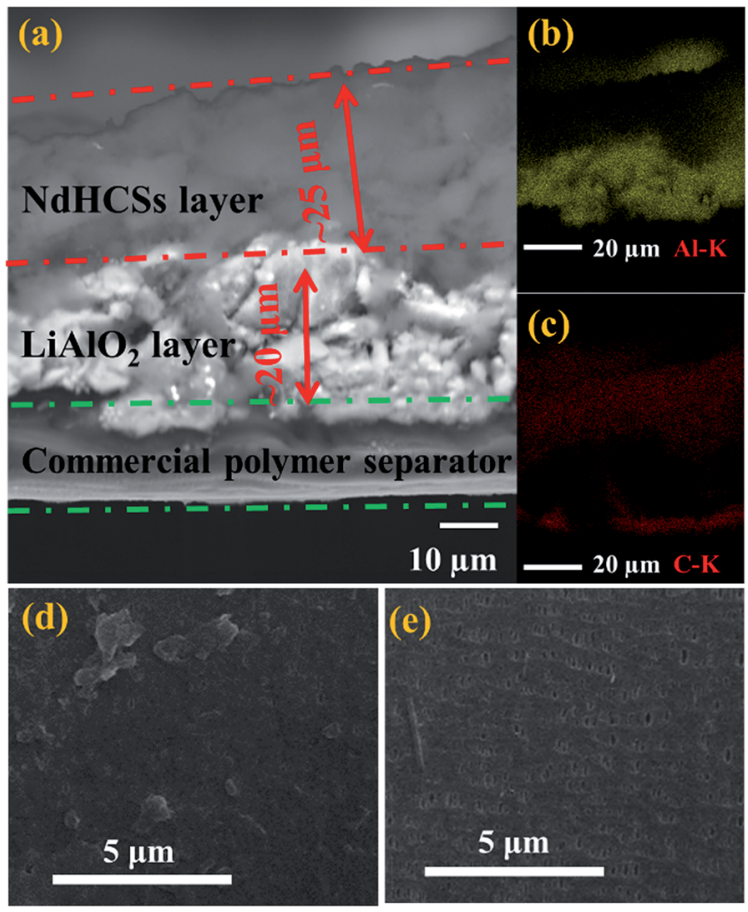

Fig. 2 SEM image (a) (cross-section view) of the $\mathrm{LiAlO}_{2} / \mathrm{NdHCSs}$ modified separator; (b) $\mathrm{Al}$ and (c) $\mathrm{C}$ element mapping from the EDS analysis of the $\mathrm{LiAlO}_{2} / \mathrm{NdHCSs}$-modified separator; top-view SEM images of (d) the $\mathrm{LiAlO}_{2} / \mathrm{NdHCSs}$-modified separator and (e) the unmodified commercial separator. (d) Top view of the side without layers.
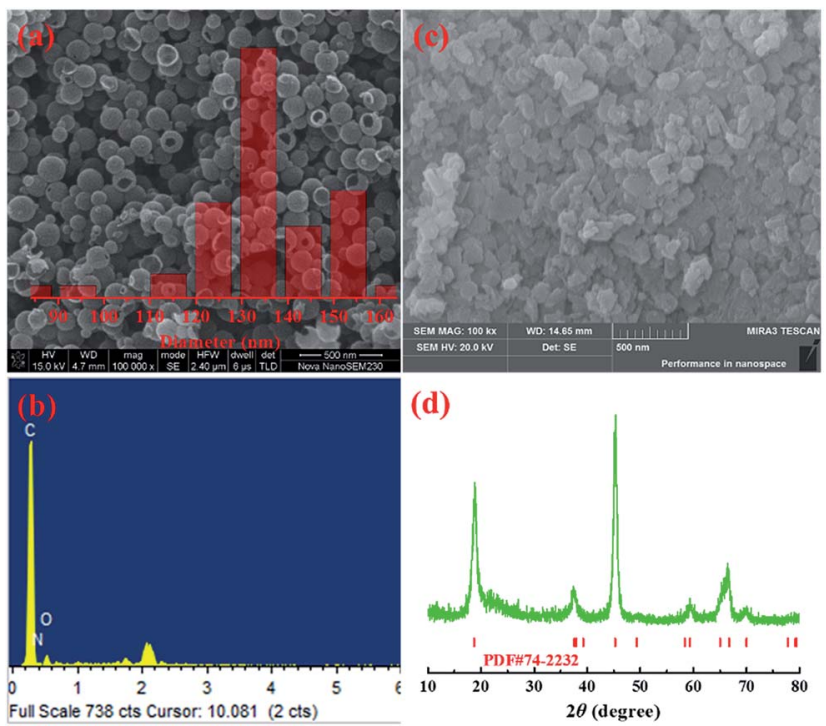

Fig. 3 (a) SEM image and size distribution (inset) of NdHCSs and (b) the corresponding EDX measurement results; (c) SEM image of $\mathrm{LiAlO}_{2}$ and (d) the XRD pattern.

pores are not observed, unlike the SEM image of the unmodified separator displayed in Fig. 2(e).

Fig. 3(a) shows the SEM image and the size distribution of the NdHCSs. It can be observed that the NdHCSs are about $140 \mathrm{~nm}$ in diameter, and their hollow structure is well preserved. A signal for the nitrogen element was detected by energy dispersive X-ray (EDX), as presented in Fig. 3(b), which demonstrates the existence of nitrogen element doped in NdHCSs. Further characterization of NdHCSs can be found in our previous study. ${ }^{45}$ Many studies have shown that the nitrogen element can increase electronic conductivity and enhance the chemical adsorbability of polysulfides. ${ }^{4-48}$ Therefore, the NdHCSs layer can possess strong absorption ability for polysulfides, thus improving the electrochemical performance of Li-S cells. Morphology of $\mathrm{LiAlO}_{2}$ was also characterized. As shown in the SEM image presented in Fig. 3(c), $\mathrm{LiAlO}_{2}$ shows irregular shapes. Fig. 3(d) displays the XRD pattern of the asprepared $\mathrm{LiAlO}_{2}$, which is in line with the $\alpha-\mathrm{LiAlO}_{2}$ crystal (JCPDS no. 74-2232), demonstrating that $\alpha-\mathrm{LiAlO}_{2}$ is successfully synthesized. $\mathrm{LiAlO}_{2}$ has been successfully coated on the surfaces of cathode materials of lithium-ion batteries, which can supply excellent lithium ion conductivity and increase the cycle stability and rate capability. ${ }^{44,49}$ Therefore, the introduced $\mathrm{LiAlO}_{2}$ is anticipated to not only absorb and block the polysulfides, but also promote the lithium-ion conductivity and increase the electrochemical performance.

The discharge/charge curves and the cyclic voltammograms (CV) of Li-S cells with a pristine separator and modified separator are shown in Fig. 4. As illustrated in Fig. 4(a and b), both cells show two discharge plateaus at $\sim 2.35$ and $2.05 \mathrm{~V}$, which correspond to the conversion of $\mathrm{S}_{8}$ to soluble polysulfides $\left(\mathrm{Li}_{2} \mathrm{~S}_{n}\right.$, $4 \leq n \leq 8)$ and their further reduction to insoluble $\mathrm{Li}_{2} \mathrm{~S} / \mathrm{Li}_{2} \mathrm{~S}_{2}$, respectively. Moreover, two charge plateaus at $\sim 2.25$ and $2.40 \mathrm{~V}$ are displayed, which correspond to the reverse reaction process, 

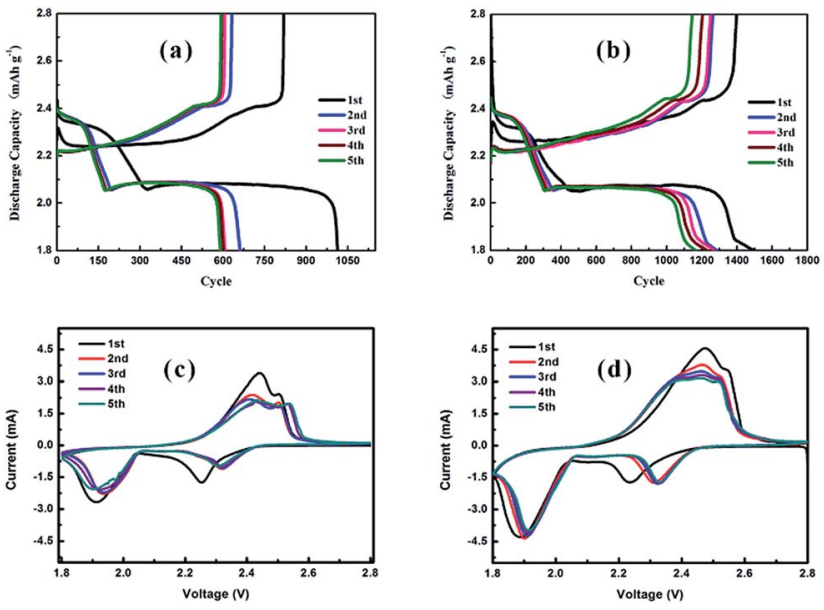

Fig. 4 The discharge/charge curves (at $0.2 \mathrm{C}$ ) of $\mathrm{Li}-\mathrm{S}$ cells (a) with pristine separator and (b) $\mathrm{LiAlO}_{2} / \mathrm{NdHCSS}$-modified separator (b). CV curves of $\mathrm{Li}-\mathrm{S}$ cells (c) with a pristine separator and (d) $\mathrm{LiAlO}_{2} /$ $\mathrm{NdHCSs-modified} \mathrm{separator.} \mathrm{The} \mathrm{sulfur} \mathrm{loading} \mathrm{of} \mathrm{the} \mathrm{tested} \mathrm{cathodes}$ is $\sim 2 \mathrm{mg} \mathrm{cm}^{-2}$.

namely $\mathrm{Li}_{2} \mathrm{~S} / \mathrm{Li}_{2} \mathrm{~S}_{2}$ to soluble polysulfides $\left(\mathrm{Li}_{2} \mathrm{~S}_{n}, 4 \leq n \leq 8\right)$ and polysulfides to $S_{8}$, respectively. ${ }^{50,51}$ In addition, the initial discharge capacities of $\mathrm{Li}-\mathrm{S}$ cells with pristine and $\mathrm{LiAlO}_{2} /$ NdHCSs-modified separators are 1013.7 and $1500 \mathrm{~mA} \mathrm{~h} \mathrm{~g}^{-1}$ at a current density of $0.2 \mathrm{C}$, respectively, and the latter indicates longer discharge plateaus and higher discharge capacities in the following discharge/charge cycles. The subsequent CV test results are in good agreement with the discharge/charge curves, as shown in Fig. 4(c and d). It is observed that the curves of the cell with the $\mathrm{LiAlO}_{2} / \mathrm{NdHCSs}$-modified separator present better overlapping, which indicates that the $\mathrm{LiAlO}_{2} / \mathrm{NdHCSs}$-modified separator can enhance the stability of the Li-S cell. Since the electrode parameters, such as the areal sulfur loading, are similar, the larger peak area also reflects the higher utilization of sulfur in the $\mathrm{Li}-\mathrm{S}$ cell with $\mathrm{LiAlO}_{2} / \mathrm{NdHCSs}$-modified separator.

Fig. 5(a) shows the rate capabilities of the cells with $\mathrm{LiAlO}_{2} /$ NdHCSs-modified separator and pristine separator. At 0.5, 1, and $2 \mathrm{C}$, the cell with the $\mathrm{LiAlO}_{2} / \mathrm{NdHCSs}$-modified separator delivered discharge capacities of 842,705 , and $480 \mathrm{~mA} \mathrm{~h} \mathrm{~g}^{-1}$, respectively. Comparatively, the cell with a pristine separator barely retained the discharge capacities of 362, 298 and $176 \mathrm{~mA} \mathrm{~h}^{-1}$. When the rate was changed back to $0.5 \mathrm{C}$, the cell with the $\mathrm{LiAlO}_{2} / \mathrm{NdHCSs}$-modified separator was able to maintain a discharge capacity of $820 \mathrm{~mA} \mathrm{~h}^{-1}$, whereas the cell with a pristine separator showed a discharge capacity of $362 \mathrm{~mA} \mathrm{~h}$ $\mathrm{g}^{-1}$. Then, the cycle performance of the $\mathrm{Li}-\mathrm{S}$ cell with $\mathrm{LiAlO}_{2} /$ NdHCSs-modified separator at different rates was investigated, as shown in Fig. 5(b). It should be pointed out that the first cycle was tested at a low current density of $0.2 \mathrm{C}$. After subsequent 100 cycles at $0.5,1$, and $2 \mathrm{C}$, the cell delivered the discharge capacities of 889.6, 786.2, and $624.8 \mathrm{~mA} \mathrm{~h} \mathrm{~g}^{-1}$ respectively, exhibiting excellent cycle stability at different rates. To further investigate the electrochemical performance of $\mathrm{Li}-\mathrm{S}$ cells, a long cycle life test was conducted at a current density of $2 \mathrm{C}$, and the first cycle
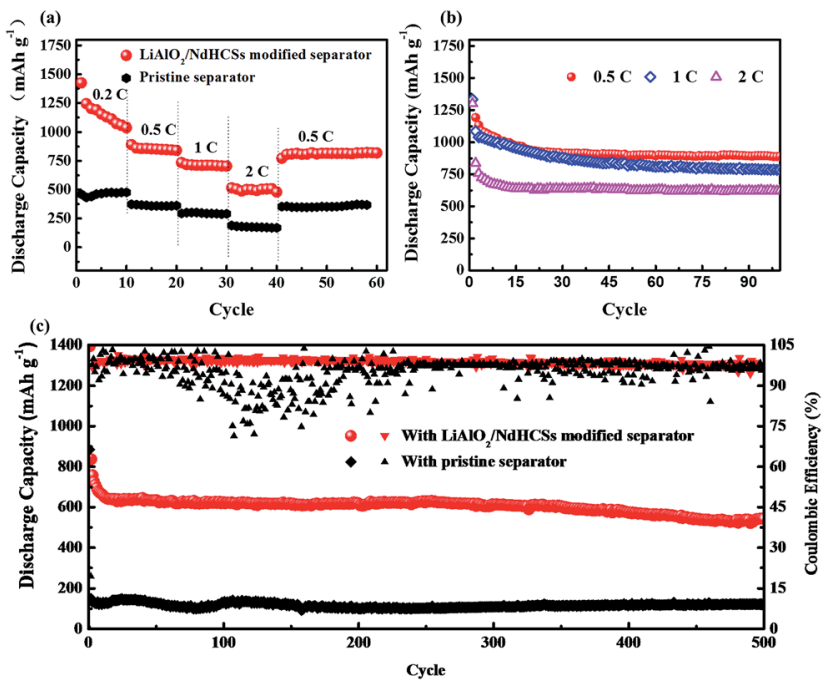

Fig. 5 (a) Rate performance of the Li-S cells with the $\mathrm{LiAlO}_{2} / \mathrm{NdHCSs}-$ modified separator and pristine separator. (b) Cycle performance of the $\mathrm{Li}-\mathrm{S}$ cell with the $\mathrm{LiAlO}_{2} / \mathrm{NdHCSs}$-modified separator at various rates of $0.5 \mathrm{C}, 1 \mathrm{C}$, and $2 \mathrm{C}$. (c) Long-term cycle performance of the $\mathrm{Li}-\mathrm{S}$ cells with the $\mathrm{LiAlO}_{2} / \mathrm{NdHCSs}$-modified separator and pristine separator at $2 \mathrm{C}$. The sulfur loading of the tested cathodes is $\sim 2 \mathrm{mg} \mathrm{cm}^{-2}$.

was tested at a low current density of 0.2C. As shown in Fig. 5(c), after 500 cycles, the discharge capacities of $543.3 \mathrm{~mA} \mathrm{~h} \mathrm{~g}^{-1}$ and $121 \mathrm{~mA} \mathrm{~h} \mathrm{~g}{ }^{-1}$ were obtained, indicating excellent cycling stability of the Li-S cell with a $\mathrm{LiAlO}_{2} / \mathrm{NdHCSs}^{-m o d i f i e d ~ s e p a-~}$ rator. In addition, the coulombic efficiency of the cell with a pristine separator showed a huge fluctuation, whereas the cell with a $\mathrm{LiAlO}_{2} / \mathrm{NdHCSs}-$ modified separator exhibited stable coulombic efficiency with an average value as high as $98.8 \%$.

To demonstrate the faster kinetics in the $\mathrm{Li}-\mathrm{S}$ cell with the $\mathrm{LiAlO}_{2} / \mathrm{NdHCSs}$-modified separator, electrochemical impedance spectra (EIS) were obtained after the first cycle. As presented in Fig. 6, the two types of cells show similar Nyquist plots with two semicircles; the first semicircle in the high frequency region is considered to be related to the solid-electrolyteinterface (SEI) film resistance, whereas the second semicircle

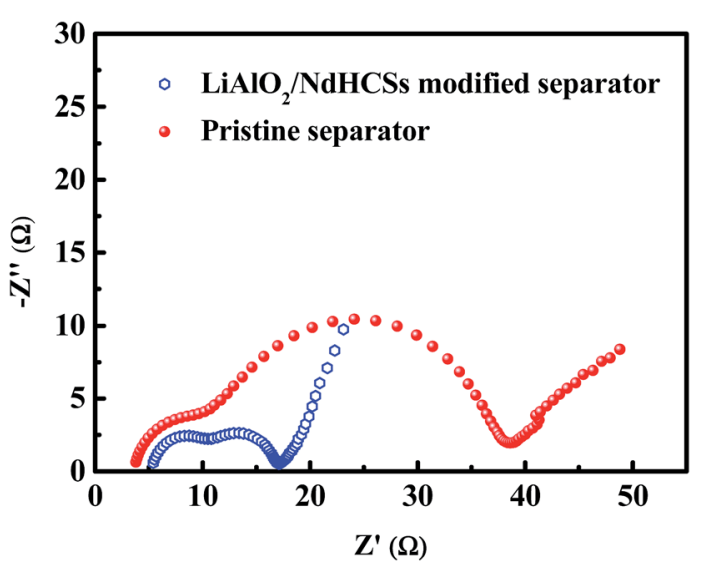

Fig. 6 EIS of the cells with the $\mathrm{LiAlO}_{2} / \mathrm{NdHCSs}$-modified separator and pristine separator. 
is related to the charge-transfer resistance $\left(R_{\mathrm{ct}}\right) .^{52}$ It can be clearly seen that the $\mathrm{Li}-\mathrm{S}$ cell with a $\mathrm{LiAlO}_{2} / \mathrm{NdHCSs}$-modified separator shows smaller charge-transfer resistance, which demonstrates that it possesses faster kinetics. This can be one of the reasons for its superior electrochemical performance. To demonstrate the adsorption ability of the NdHCSs to polysulfides, ex situ adsorption measurements were carried out by immersing NdHCSs in a $\mathrm{Li}_{2} \mathrm{~S}_{6}$ solution $\left(5 \mathrm{~mL}, 0.04 \mathrm{mmol} \mathrm{L}^{-1}\right)$. Then, the color change was determined by a camera. As presented in the images shown in Fig. S1 (ESI $\dagger$ ), the solution with the NdHCSs powder clearly faded after $72 \mathrm{~h}$. To demonstrate that $\mathrm{LiAlO}_{2}$ could restrict the shuttle of the dissolved polysulfides, the electrochemical performance of a cell with a $\mathrm{LiNO}_{3}$ free electrolyte and a $\mathrm{LiAlO}_{2}$-modified separator was measured. As presented in Fig $\mathrm{S} 2(\mathrm{a}), \uparrow$ the coulombic efficiency is noticeably enhanced with the $\mathrm{LiAlO}_{2}$-modified separator, which demonstrates that $\mathrm{LiAlO}_{2}$ can effectively restrict the shuttle effect. The $\mathrm{LiAlO}_{2} / \mathrm{NdHCSs}$-modified separator further enhances the coulombic efficiency. It also renders a better rate performance, as illustrated in Fig. S2(b). $\dagger$

Fig. 7(a) shows the cycle performance of $\mathrm{Li}-\mathrm{S}$ cells with different separators. The first cycle was tested at a low current density of $0.2 \mathrm{C}$, and, the following cycles were conducted at $1 \mathrm{C}$. $\mathrm{Li}-\mathrm{S}$ cells with the pristine separator, $\mathrm{LiAlO}_{2}$-modified separator, NdHCSs-modified separator, and $\mathrm{LiAlO}_{2} / \mathrm{NdHCSs}^{-}$ modified separator revealed an increment of initial discharge
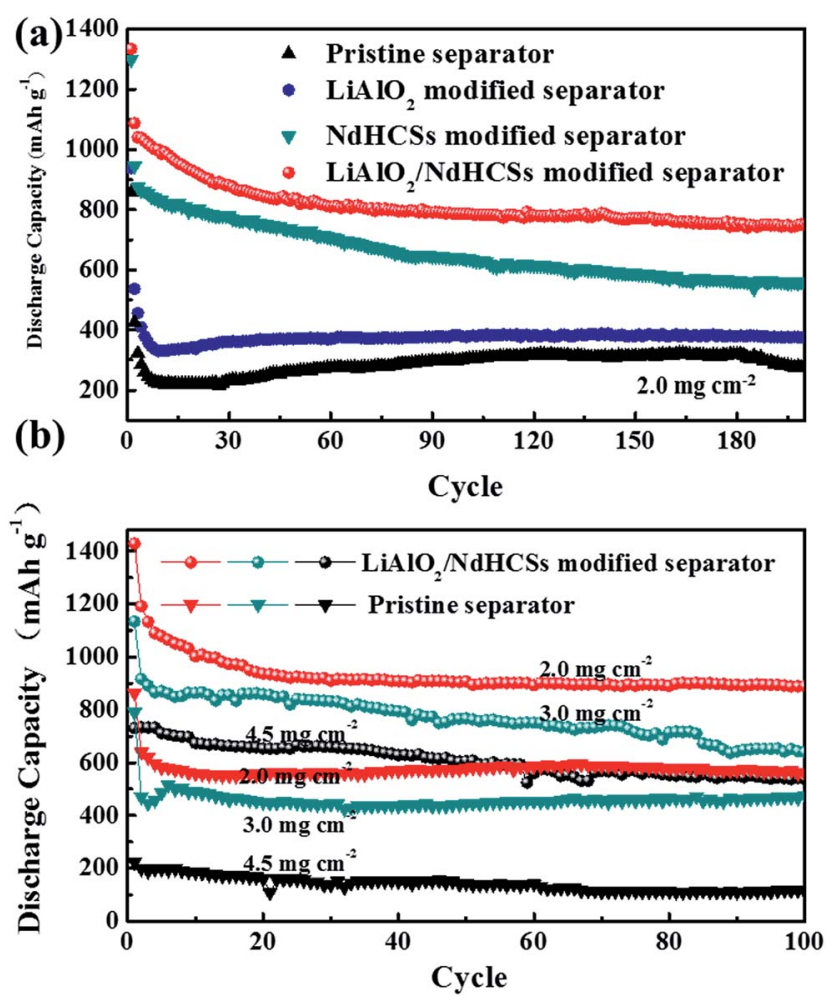

Fig. 7 (a) The cycle performance of $\mathrm{Li}-\mathrm{S}$ cells (sulfur loading = $\sim 2.0 \mathrm{mg} \mathrm{cm}^{-2}$ ) with the pristine separator, $\mathrm{LiAlO}_{2}$-modified separator, $\mathrm{NdHCSs}$-modified separator, and $\mathrm{LiAlO}_{2} / \mathrm{NdHCSs}$-modified separator at $1 \mathrm{C}$; (b) the cycle performance of $\mathrm{Li}-\mathrm{S}$ cells with the pristine separator and $\mathrm{LiAlO}_{2} / \mathrm{NdHCSs}$-modified separator with different areal densities $\left(2.0,3.0\right.$, and $\left.4.5 \mathrm{mg} \mathrm{cm}^{-2}\right)$ of active materials. capacities in sequence. Moreover, the cells respectively maintained the discharge capacities of 276.1, 376.3, 559.4, and $749 \mathrm{~mA} \mathrm{~h} \mathrm{~g}^{-1}$ after 200 cycles, and the capacity retention rates were $32.2 \%, 40.1 \%, 43.1 \%$, and $56.2 \%$, respectively. It can be concluded that the $\mathrm{LiAlO}_{2} / \mathrm{NdHCSs}$-modified separator can effectively improve the cycle stability of $\mathrm{Li}-\mathrm{S}$ cells, and the utilization rate of the active material is significantly enhanced. To further investigate the influence of the $\mathrm{LiAlO}_{2} / \mathrm{NdHCSs}^{-}$ modified separator on Li-S cells, cells with different areal densities of active materials were assembled and tested, as shown in Fig. 7(b). The first cycle was tested at a low current density of $0.2 \mathrm{C}$, and the following cycles were conducted at $0.5 \mathrm{C}$. We found that the initial discharge capacities of Li-S cells decreased with the increasing areal densities. When the areal sulfur loading was $2.0,3.0$, and $4.5 \mathrm{mg} \mathrm{cm}^{-2}$, Li-S cells with pristine separators maintained the discharge capacities of $560.3,475.2$, and $114.1 \mathrm{~mA} \mathrm{~h} \mathrm{~g}^{-1}$ after 100 cycles, whereas the cells with $\mathrm{LiAlO}_{2} / \mathrm{NdHCSs}-$ modified separators showed the great discharge capacities of 889.6, 640, and $538.6 \mathrm{~mA} \mathrm{~h} \mathrm{~g}^{-1}$.

The results demonstrate that the $\mathrm{LiAlO}_{2} / \mathrm{NdHCSs}$-modified separator can greatly improve the energy density of Li-S cells. The $\mathrm{LiAlO}_{2}$ bottom layer on the separator not only blocks the dissolved polysulfides to restrict their shuttling, but also provides fast ionic channels for the transfer $\mathrm{Li}^{+}$ions. Moreover, the upper NdHCSs layer not only works as a second current collector to provide more active sites for the redox reaction, but also restricts the shuttle of polysulfides. As a result, the $\mathrm{LiAlO}_{2} /$ NdHCSs-modified separator shows great potential for prospective applications of $\mathrm{Li}-\mathrm{S}$ batteries.

\section{Conclusions}

In conclusion, a novel double-layer $\mathrm{LiAlO}_{2} / \mathrm{NdHCSs}$-modified separator was prepared to improve the poor cycle stability and fast capacity fading of Li-S cells. The modified separator exhibits significant inhibition of shuttle effect and high utilization of active materials. With the $\mathrm{LiAlO}_{2} / \mathrm{NdHCSs}$-modified separator, a high initial discharge capacity of $1500 \mathrm{~mA} \mathrm{~h} \mathrm{~g}{ }^{-1}$ was achieved at $0.2 \mathrm{C}$, and a discharge capacity of $543.3 \mathrm{~mA} \mathrm{~h} \mathrm{~g}^{-1}$ was obtained after 500 cycles at 2C. Especially, when the areal density of the active material was increased to $4.5 \mathrm{mg} \mathrm{cm}^{-2}$, the cells retained a discharge capacity of $538.6 \mathrm{~mA} \mathrm{~h} \mathrm{~g}^{-1}$ after 100 cycles at $0.5 \mathrm{C}$. The NdHCSs make direct contacts to the $\mathrm{S}$ cathode while serving as an upper collector and the first absorption layer. Moreover, $\mathrm{LiAlO}_{2}$ can offer more $\mathrm{Li}^{+}$transportation channels and serves as the second absorption layer. Therefore, the double-layer $\mathrm{LiAlO}_{2} /$ NdHCSs-modified separator shows great potential for further practical applications of $\mathrm{Li}-\mathrm{S}$ batteries.

\section{Conflicts of interest}

There are no conflicts of interest to declare.

\section{Acknowledgements}

This research was supported by the Chinese National Natural Science Foundation (51474243, 51574288). The authors 
acknowledge the financial support provided by the Project of Innovation Driven Plan in Central South University (2015CXS018) and (2015CX001).

\section{Notes and references}

1 S. Zhao, Y. Wang, J. Dong, C. T. He, H. Yin, P. An, K. Zhao, X. Zhang, C. Gao, L. Zhang, J. Lv, J. Wang, J. Zhang, A. M. Khattak, N. A. Khan, Z. Wei, J. Zhang, S. Liu, H. Zhao and Z. Tang, Nat. Energy, 2016, 1, 16184.

2 S. Zhao, H. Yin, L. Du, L. He, K. Zhao, L. Chang, G. Yin, H. Zhao, S. Liu and Z. Tang, ACS Nano, 2014, 8, 12660.

3 M. Wild, L. O'Neill, T. Zhang, R. Purkayastha, G. Minton, M. Marinescu and G. J. Offer, Energy Environ. Sci., 2015, 8, 3477.

4 X. Ji, K. T. Lee and L. F. Nazar, Nat. Mater., 2009, 8, 500.

5 A. Manthiram, S. H. Chung and C. Zu, Adv. Mater., 2015, 27, 1980.

6 G. Q. Ma, Z. Y. Wen, J. Jin, Y. Lu, X. W. Wu, M. F. Wu and C. H. Chen, J. Mater. Chem. A, 2014, 2, 10350.

7 Z. Zhang, Q. Li, K. Zhang, Y. Lai and J. Li, Electrochim. Acta, 2015, 152, 53.

8 Z. Li, Y. Huang, L. Yuan, Z. Hao and Y. Huang, Carbon, 2015, 92, 41.

9 L. Chen and L. L. Shaw, J. Power Sources, 2014, 267, 770.

10 Y. X. Yin, S. Xin, Y. G. Guo and L. J. Wan, Angew. Chem., Int. Ed. Engl., 2013, 52, 13186.

11 X. Fang and H. Peng, Small, 2015, 11, 1488.

12 P. G. Bruce, S. A. Freunberger, L. J. Hardwick and J. M. Tarascon, Nat. Mater., 2012, 11, 19.

13 X. Ji and L. F. Nazar, J. Mater. Chem., 2010, 20, 9821.

14 G. Ma, Z. Wen, Q. Wang, C. Shen, P. Peng, J. Jin and X. Wu, J. Power Sources, 2015, 273, 511.

15 A. Manthiram, Y. Fu, S. H. Chung, C. Zu and Y. S. Su, Chem. Rev., 2014, 114, 11751.

16 G. Xu, B. Ding, J. Pan, P. Nie, L. Shen and X. Zhang, J. Mater. Chem. A, 2014, 2, 12662.

17 R. Chen, T. Zhao and F. Wu, Chem. Commun., 2015, 51, 18. 18 D.-W. Wang, Q. Zeng, G. Zhou, L. Yin, F. Li, H.-M. Cheng, I. R. Gentle and G. Q. M. Lu, J. Mater. Chem. A, 2013, 1, 9382.

19 M. Rao, X. Song, H. Liao and E. J. Cairns, Electrochim. Acta, 2012, 65, 228.

20 T. Xu, J. Song, M. L. Gordin, H. Sohn, Z. Yu, S. Chen and D. Wang, ACS Appl. Mater. Interfaces, 2013, 5, 11355.

21 K. Mi, S. Chen, B. Xi, S. Kai, Y. Jiang, J. Feng, Y. Qian and S. Xiong, Adv. Funct. Mater., 2017, 27, 1604265.

22 M.-Q. Zhao, X.-F. Liu, Q. Zhang, G.-L. Tian, J.-Q. Huang, W. Zhu and F. Wei, ACS Nano, 2012, 6, 10759.

23 J. Wang, J. Chen, K. Konstantinov, L. Zhao, S. H. Ng, G. X. Wang, Z. P. Guo and H. K. Liu, Electrochim. Acta, 2006, 51, 4634.

24 G. Ma, Z. Wen, J. Jin, Y. Lu, X. Wu, M. Wu and C. Chen, J. Mater. Chem. A, 2014, 2, 10350.

25 W. Zhou, Y. Yu, H. Chen, F. J. DiSalvo and H. D. Abruna, J. Am. Chem. Soc., 2013, 135, 16736.

26 B. Ding, L. Shen, G. Xu, P. Nie and X. Zhang, Electrochim. Acta, 2013, 107, 78.
27 Z. A. Ghazi, L. Zhu, H. Wang, A. Naeem, A. M. Khattak, B. Liang, N. A. Khan, Z. Wei, L. Li and Z. Tang, Adv. Energy Mater., 2016, 6, 1601250.

28 S.-H. Chung and A. Manthiram, Adv. Funct. Mater., 2014, 24, 5299.

29 H. Wei, J. Ma, B. Li, Y. Zuo and D. Xia, ACS Appl. Mater. Interfaces, 2014, 6, 20276.

30 S. H. Chung and A. Manthiram, Adv. Mater., 2014, 26, 7352.

31 C. Zu, Y. S. Su, Y. Fu and A. Manthiram, Phys. Chem. Chem. Phys., 2013, 15, 2291.

32 T. G. Jeong, Y. H. Moon, H. H. Chun, H. S. Kim, B. W. Cho and Y. T. Kim, Chem. Commun., 2013, 49, 11107.

33 Y. S. Su and A. Manthiram, Nat. Commun., 2012, 3, 1166.

34 J. Fang, F. Qin, J. Li, K. Zhang, W. Liu, M. Wang, F. Yu and L. Zhang, J. Power Sources, 2015, 297, 265.

35 J. Balach, T. Jaumann, M. Klose, S. Oswald, J. Eckert and L. Giebeler, Adv. Funct. Mater., 2015, 25, 5285.

36 G. C. Li, H. K. Jing, Z. Su, C. Lai, L. Chen, C. C. Yuan, H. H. Li and L. Liu, J. Mater. Chem. A, 2015, 3, 11014.

37 J.-Q. Huang, Q. Zhang, H.-J. Peng, X.-Y. Liu, W.-Z. Qian and F. Wei, Energy Environ. Sci., 2014, 7, 347.

38 Z. Zhang, Y. Lai, Z. Zhang, K. Zhang and J. Li, Electrochim. Acta, 2014, 129, 55.

39 W. Li, J. Hicks-Garner, J. Wang, J. Liu, A. F. Gross, E. Sherman, J. Graetz, J. J. Vajo and P. Liu, Chem. Mater., 2014, 26, 3403.

40 W. B. Kong, L. J. Yan, Y. F. Luo, D. T. Wang, K. L. Jiang, Q. Q. Li, S. S. Fan and J. P. Wang, Adv. Funct. Mater., 2017, 27, 1606663.

41 Z. A. Ghazi, X. He, A. M. Khattak, N. A. Khan, B. Liang, A. Iqbal, J. Wang, H. Sin, L. Li and Z. Tang, Adv. Mater., 2017, 29, 1606817.

42 S. Bai, X. Liu, K. Zhu, S. Wu and H. Zhou, Nat. Energy, 2016, 1, 16094.

43 L. Li, Z. Chen, Q. Zhang, M. Xu, X. Zhou, H. Zhu and K. Zhang, J. Mater. Chem. A, 2015, 3, 894.

44 H. S. Kim, Y. Kim, S. I. Kim and S. W. Martin, J. Power Sources, 2006, 161, 623.

45 Z. Zhang, G. Wang, Y. Lai, J. Li, Z. Zhang and W. Chen, J. Power Sources, 2015, 300, 157.

46 X. Wang, Z. Zhang, Y. Qu, Y. Lai and J. Li, J. Power Sources, 2014, 256, 361.

47 F. Sun, J. Wang, H. Chen, W. Li, W. Qiao, D. Long and L. Ling, ACS Appl. Mater. Interfaces, 2013, 5, 5630.

48 X. G. Sun, X. Wang, R. T. Mayes and S. Dai, ChemSusChem, 2012, 5, 2079.

49 F. Cheng, Y. Xin, Y. Huang, J. Chen, H. Zhou and X. Zhang, J. Power Sources, 2013, 239, 181.

50 Q. Li, Z. Zhang, K. Zhang, J. Fang, Y. Lai and J. Li, J. Power Sources, 2014, 256, 137.

51 R. Singhal, S.-H. Chung, A. Manthiram and V. Kalra, J. Mater. Chem. A, 2015, 3, 4530.

52 S. Zhao, Y. Li, H. Yin, Z. Liu, E. Luan, F. Zhao, Z. Tang and S. Liu, Sci. Adv., 2015, 1, e1500372. 